\title{
Effectiveness of low volume acute normovolemic hemodilution in patients undergoing off pump coronary artery bypass grafting surgery
}

\author{
Authors \\ Premraj Nagarwal $^{1}$, Gaurav Goyal ${ }^{2 *}$, Jeevraj Singh Rajawat ${ }^{1}$, Saurabh Gupta ${ }^{1}$ \\ ${ }^{1}$ Assistant Professor, ${ }^{2}$ Associate Professor, Department of Cardiac Anesthesia, Mahatma Gandhi Medical \\ College and Hospital, Sitapura, Jaipur (Raj). 302022 \\ *Corresponding Author \\ Dr Gaurav Goyal \\ Associate Professor, Department. of Cardiac Anesthesia, Mahatma Gandhi Medical College and Hospital, \\ Sitapura, Jaipur(Raj.) Pin 302022, India
}

\begin{abstract}
Background: The objective of this study was to evaluate the effectiveness of low volume acute normovolemic hemodilution (LVANH) in patients undergoing primary elective off pump coronary artery bypass graft $(O P C A B)$ surgery.

Methods: Sixty patients undergoing primary elective OPCAB surgery were prospectively randomized into two groups: Group LVANH $(n=30)$ and Group $C(n=30)$ as control. Autologous blood was removed $(<4$ $\mathrm{ml} / \mathrm{kg}$ but more than $200 \mathrm{ml}$ ) of estimated blood volume in patients with hemoglobin $(\mathrm{Hb})>12 \mathrm{~g} \%$ to keep hematocrit more than 30\% after acute normovolumic hemodilutuion for subsequent re-transfusion after protamine administration from group LVANH, while no blood was withdrawn from control group. The autologous blood withdrawn was replaced simultaneously with an equal volume of hydroxyl-ethyl starch solution in group LVANH patients only. Allogenic blood was transfused in both the groups when Hb was $\leq 8.5 \mathrm{~g} \%$. Total post operative drain and requirement of postoperative allogenic blood transfusion along with any adverse events were evaluated.

Results: The two groups were comparable in regards of demographic data, type of surgical procedures performed, duration of surgery. Both groups have comparable hemaocrit and ACT levels at the time of shifting to post operative cardiac surgery unit without any added ischemic or hemodynamic intraoperative events. During first and fourth hour of recovery period, amount of blood drainage is significantly reduced in LVANH group but after twenty four hours amount of total blood drain is comparable. Perioperative blood transfusion requirements were also not statistically different. No patient in any of the groups suffered major adverse cardiac event. Patients were extubated, shifted out of intensive care unit and discharged home with comparable time periods.

Conclusion: We conclude that low volume autologous blood transfusion procedure is safe and can be done without any added risk to selected patients those are posted for off pump cardiac surgery. This method of blood salvage may have importance during first four hours of surgery but had no advantage after that period on perioperative blood loss and transfusion requirements.

Keywords: Low volume acute normovolemic hemodilution, off pump coronary artery bypass graft surgery.
\end{abstract}




\section{Objective}

Blood salvage is a major concern during cardiac surgeries as recent evidence suggests allogenic blood transfusion results in negative outcome in terms of increased morbidity and mortality, prolonged hospital stay and decrease in long-term quality of life ${ }^{1}$.

Acute normovolemic autologous blood withdrawal and retransfusion post surgery is one of the strategies for blood salvage during on pump cardiac surgery ${ }^{2}$. Usually $6-8 \mathrm{ml} / \mathrm{kg}$ blood is collected in standard CPDA bag prior to heparinization so that hematocrit remained more than $25 \%$ after isovolumic hemodilution during extra corporeal circulation, which is transfused back to patient after hemostatis and protamine. ${ }^{3}$ This autologous blood provides advantages of not only increases hemoglobin but also replaces platelets and coagulation factors ${ }^{4}$.

Patients planned for off pump coronary artery bypass graft surgeries which are done on beating heart without the use of extra corporeal circulation require more hematocrit (30\%). In these patients, myocardium is at the increased risk of ischemia during low cardiac output stages which occurs with manipulation of heart at time of coronary grafting ${ }^{5}$. It is not prudent to take full volume autologous blood in these patients. Our objective is to study utility of low volume acute normovolumic hemodilution $(<4 \mathrm{ml} / \mathrm{kg}$ but more than 200ml) with target hematocrit of not less than $30 \%$ can be safely collected from these patients and replaced after protamine will able to decrease perioperative drainage and allogenic blood transfusions.

\section{Methods}

After getting approval from institutional ethical board, patients who were planned for off pump coronary artery bypass graft surgery with stable cardio vascular status and controlled comorbidities, having preoperative hematocrit more than $36 \%$ were included in this study. Informed consent was taken. Preoperative exclusion criteria were body weight less than $50 \mathrm{~kg}$, left ventricular ejection fraction (LVEF) less than 40\%, associated valvular lesions, preoperative hematocrit less than $36 \%$ or hemoglobin less than $12 \mathrm{~g} / \mathrm{dl}$, history of hematologic diseases, more than mild renal impairment (plasma creatinine $>1.4 \mathrm{mg} / \mathrm{dl}$ ), history of hepatic diseases (e.g. active hepatitis or cirrhosis) and re-do surgeries . Preoperative treatment with aspirin or heparin was not a contraindication to enrolment in this study.

A standardized protocol for anesthesia was applied. Induction and maintenance of anesthesia were performed with propofol (response titrated bolus of $1-2 \mathrm{mg} / \mathrm{kg}$, midazolam $0.05 \mathrm{mg} / \mathrm{kg}$ and fentanyl (bolus of 3-5 $\mu \mathrm{g} / \mathrm{kg}$ ). Muscle relaxation was obtained with vecuronium or pancuronium bromide (bolus of $0.1 \mathrm{mg} / \mathrm{kg}$ and further administrations of $0.03 \mathrm{mg} / \mathrm{kg}$ hourly). Isoflurane was added after induction and patients were ventilated on closed circuit system with end tidal carbondioxide value of $35 \mathrm{mmHg}$.

By using a computer-generated random number sequence, the 60 patients were prospectively randomized, into two groups: the LVANH group (30 patients) and the control group (30 patients). In the LVANH group patients, less than $4 \mathrm{ml} / \mathrm{kg}$ but above $200 \mathrm{ml}$ of pre calculated blood was withdrawn after the induction of anesthesia and before systemic heparinization to keep hematocrit above $30 \%$ after acute normovolumic hemodilution (ANH). Calculation for amount of blood withdrawn was done according to Gross formula $^{1}$ that is patient hematocrit minus target hematocrit divided by patients hematocrit and multiply by total blood volume. The blood was withdrawn through a large bore catheter placed into the internal jugular vein, with gravity drainage, to limit shear effects on the platelets. During the withdrawal of the autologous blood, a colloid solution was infused (Volulyte 6\% HES 130/0.4, Fresinus Kabi) in 1:1 ratio. This blood was collected into sterile standard CPDA blood collection bags containing citrate phosphate dextrose anticoagulant (Terumo Penpol, India). In group $\mathrm{C}$ aptients, no autologous blood was withdrawn and hemodilution with colloids was not done. In both groups, crystalloids were infused 
if hemodynamic status required. Isovolemia was evaluated through standard monitoring (systemic arterial pressure, electrocardiogram, pulmonary artery pressure and central venous pressure). Autologous blood withdrawn was labeled with the patient's identification and stored at room temperature in the operating room.

The same team of surgeons, with standardized surgical procedures, did all the interventions. All patients were operated on through full median sternotomy. Before coronary arteriotomy, porcine heparin, was administered to keep activated clotting time (ACT) above 300 sec. and off pump coronary artery bypass graft surgery performed using medtronic heart stabilizers (octopus). The blood drawn before surgery from the LVANH group patients was reinfused at the end of surgery after protamine and before transporting patients to the intensive care unit (ICU). Intra- and postoperative criteria for allogeneic transfusions were standardized. These criteria were applied in the LVANH group only after the reinfusion of the autologous blood withdrawn. Packed red blood cells (PRBC) were transfused, during surgery if hemoglobin value was less than $8.5 \mathrm{~g} / \mathrm{dl}$ and hematocrit value was less than $26 \%$ at any point of time to all the patients.
Fresh frozen plasma (FFP) was infused, after protamine administration, if prothrombin time value was 1.5 times the basal in presence of active bleeding. Platelet concentrates (PLTC) were transfused in presence of active bleeding and of a platelet count less than $50,000 / \mathrm{mm}^{3}$. Samples for evaluation of hemoglobin, leucocyte count, platelet count, activated clotting time (ACT), creatininewere performed before the induction of anesthesia(time:T1), on arrival in ICU(time T2), $24 \mathrm{~h}$ after the arrival in ICU(time T3), shifting to step down from ICU after surgery (time T4) and at discharge (timeT5). Further determinations of these variables were made as the clinical situation required.

Blood loss was recorded during the first $24 \mathrm{~h}$.

Surgical re-exploration was decided on when bleeding in the first $2 \mathrm{~h}$ was greater than $300 \mathrm{ml} / \mathrm{h}$ or if greater than $200 \mathrm{ml} / \mathrm{h}$ for 4 consecutive $\mathrm{h}$, with normal coagulation data. Intubation time, ICU stay, hospitalization, major complications (e.g ., perioperative myocardial infarction, renal insufficiency, pulmonary embolism, stroke), and mortality were considered.

\section{Results}

Table 1 Demographic data

\begin{tabular}{|l|c|c|c|}
\hline Variable & Control & LVANH & P value \\
\hline AGE (years) & $59.4 \pm 12.9$ & $63.7 \pm 17.2$ & 0.278 \\
\hline SEX (M: F) & $18: 12$ & $16: 14$ & \\
\hline WEIGHT (kg) & $63.6 \pm 19.8$ & $69.2 \pm 15.3$ & 0.225 \\
\hline LV EF & 12 & & \\
$40 \%-50 \%$ & 18 & 14 & 0.27 \\
$50 \%-60 \%$ & 3 & 16 & \\
\hline NYHA Class & & 3 & \\
\hline Vessels grafts count & 7 & 9 & \\
2 (lima +1 rsv graft) & 23 & 21 & 0.67 \\
3 (lima +2 rsv graft) & 14 & & \\
\hline Co Morbidity & 18 & 16 & 0.27 \\
I. DM & 9 & 5 & 0.97 \\
II. HTN & 4 & 3 & 0.38 \\
III. HYPOTHYROID & & & \\
IV. Rn.Insufficiency & 6 & 8 & 0.27 \\
\hline Sr.Creat: 1.2-1.4 & & & \\
\hline Pre op. Asprin up to 2days & 6 & & \\
\hline
\end{tabular}


Table 2 Post operative data

\begin{tabular}{|l|c|c|c|}
\hline Variable & Control Gr. & LVANH Gr. & P value \\
\hline Duration of sugery & $239 \pm 67 \mathrm{~min}$ & $266 \pm 42 \mathrm{~min}$ & 0.067 \\
\hline Intervention during grafting & 0 & 0 & \\
\hline Coversion to onpump / iabp & 0 & 0 & \\
\hline Postoperative act & $145 \pm 23$ & $129 \pm 29$ & 0.109 \\
\hline Post operative hct & $29 \pm 7 \%$ & $31 \pm 9 \%$ & 0.341 \\
\hline Extubation time & $324 \pm 63 \mathrm{~min}$ & $347 \pm 56 \mathrm{~min}$ & 0.14 \\
\hline
\end{tabular}

Table 3 Post operative bleeding

\begin{tabular}{|l|c|c|c|}
\hline Post operative bleeding & & & \\
$\mathbf{1}^{\text {st }} \mathbf{h r}$. & $\mathbf{8 0} \pm \mathbf{4 5} \mathbf{~ m l}$ & $\mathbf{5 0} \pm \mathbf{5 2} \mathbf{~ m l}$ & $\mathbf{0 . 0 2}$ \\
$2^{\text {nd }}$ hr. & $68 \pm 36 \mathrm{ml}$ & $76 \pm 32 \mathrm{ml}$ & 0.36 \\
$3^{\text {rd }} \mathbf{h r}$ & $72 \pm 45 \mathrm{ml}$ & $90 \pm 43 \mathrm{ml}$ & 0.056 \\
$\mathbf{4}^{\text {th }} \mathbf{h r}$ & $\mathbf{9 0 \pm 4 8} \mathbf{~ m l}$ & $\mathbf{6 2} \pm \mathbf{5 7} \mathbf{~ m l}$ & $\mathbf{0 . 0 4 4}$ \\
\hline Bl loss 24 hr. & $553 \pm 65$ & $528 \pm 45 \mathrm{ml}$ & 0.089 \\
\hline Pt. Require BT & $19 / 30$ & $17 / 30$ & 0.89 \\
\hline Total no. of BT & & & \\
PRBC & 25 & 22 & 1 \\
FFP & Nil & Nil & \\
PL. & Nil & Nil & \\
\hline
\end{tabular}

Table 4 Post operative data

\begin{tabular}{|l|c|c|c|c|c|c|c|c|c|c|}
\hline & \multicolumn{9}{|c|}{ Group C } & \multicolumn{5}{c|}{ Group LVANH } \\
\hline & T1 & T2 & T3 & T4 & T5 & T1 & T2 & T3 & T4 & T5 \\
\hline Hct\% & 38 & 28 & 27.5 & 28.2 & 29 & 37 & 30 & 28 & 27.5 & 28 \\
$( \pm 2$ SD $)$ & $(7.2)$ & $(5.1)$ & $(5.7)$ & $(5.9)$ & $(6.1)$ & $(6.9)$ & $(6.1)$ & $(4.9)$ & $(6.3)$ & $(6.6)$ \\
\hline TLC10 & 10.7 & 12.3 & 13.45 & 13.0 & 11.37 & 10.5 & 11.4 & 13.7 & 12.2 & 11.2 \\
$( \pm 2 S D)$ & $(1.8)$ & $(2.3)$ & $(2.6)$ & $(1.9)$ & $(2.4)$ & $(2.1)$ & $(2.9)$ & $(2.6)$ & $(2.9)$ & $(2.9)$ \\
\hline Plt.10 & 1.58 & 1.26 & 1.26 & 1.20 & 1.38 & 1.42 & 1.38 & 1.32 & 1.28 & 1.32 \\
$( \pm 2$ SD $)$ & $(0.4)$ & $(0.2)$ & $(0.31)$ & $(0.19)$ & $(2.7)$ & $(0.19)$ & $(0.28)$ & $(0.25)$ & $(0.31)$ & $(0.29)$ \\
\hline ACT.sec & 128 & 152 & 132 & 130 & 132 & 133 & 146 & 130 & 126 & 128 \\
$( \pm 2$ SD $)$ & $(23.7)$ & $(22.6)$ & $(23.8)$ & $(27.3)$ & $(21.8)$ & $(27.9)$ & $(32.8)$ & $(29.4)$ & $(23.9)$ & $(27.1)$ \\
\hline Cr.mg/dl & 1.1 & 1.2 & 1.1 & 1.2 & 1.2 & 1.08 & 1.2 & 1.18 & 1.15 & 1.2 \\
$( \pm 2 S D)$ & $(0.3)$ & $(0.2)$ & $(0.1)$ & $(0.2)$ & $(0.1)$ & $(0.2)$ & $(0.12)$ & $(0.19)$ & $(0.17)$ & $(0.16)$ \\
\hline
\end{tabular}

Table 5 Adverse Events Data

\begin{tabular}{|l|c|c|c|}
\hline & Group C & Group LVANH & \\
\hline Fever $>38.5^{\circ} \mathrm{C}$ & 3 & 4 & $>0.05$ \\
\hline Leukocytosis & 2 & 3 & $>0.05$ \\
\hline Sternal wound inf. & 1 & 0 & $>0.05$ \\
\hline inotropes $>$ Mild dose & 7 & 9 & $>0.05$ \\
\hline Arrhythmias & 0 & 0 & \\
\hline Reintubation & 0 & 0 & \\
\hline Re Exploration & 0 & 0 & \\
\hline Tamponade & 0 & 0 & \\
\hline LOS ICU >3d & 4 & 3 & $>0.05$ \\
\hline LOS Hospital $>7 \mathrm{~d}$ & 3 & 3 & $>0.05$ \\
\hline
\end{tabular}

\section{Discussion}

Cardiac surgery is responsible for approximately $20 \%$ of allogenic blood transfusion. ${ }^{7}$ However, the transfusion rate has been decreased considerably in recent years. ${ }^{8}$ This has been mainly due to advancement in surgical expertise as well as better understanding of the physiology of blood transfusion which has led to lower transfusion trigger ${ }^{9}$. In addition, the use of newer antifibrinolytics drug, blood salvage techniques and guidelines by ASA 2015 guidelineshave also contributed to the decrease in transfusion requirements. ${ }^{10}$ The efficacy of ANH is still controversial with only some studies 
demonstrating the benefit of ANH in cardiac surgery $^{11}$. These have mostly been in patients undergoing coronary artery bypass grafting on cardiopulmonary bypass in whom large volume of autologous blood (700-1000 mL) was withdrawn $^{12}$. Few others have demonstrated ANH with withdrawal of $5-8 \mathrm{~mL} / \mathrm{kg}$ or $400 \mathrm{~mL}^{13}$ of blood. But to remove this amount of blood from patients who are at the risk for myocardial ischemia is not approved by most of the cardiac surgeons. Our desire to study the effects of lowvolume $\mathrm{ANH}$ on patients undergoing $\mathrm{OPCAB}$ surgery derives from the fact that these patients are considered to be at increased risk for perioperative excessive bleeding, therefore theoretically more benefits may be achevied by the application of autologous blood transfusion to this group of patients. Segal et al. ${ }^{14}$ in their metaanalysis report that only a modest hemostatic benefit is seen with ANH and that the clinical benefit of reducing blood loss by small volume is unknown.We designed this study for assessment of benefit gained with the use of low volume acute normovolumic blood transfusion in selected off pump cardiac surgery patients.

In our study both groups were comparable in terms of demographic data, comorbidity, pre operative nature of disease and duration of surgery. (Table 1)

Analysis of post operative data shows both groups have comparable hemaocrit and ACT levels at the time of shifting to post operative cardiac surgery unit without any added ischemic or hemodynamic events. (Table 2). This reflects safe method of normovolumic hemodilution with use of $6 \%$ 130/0.4 HES colloid solution. As none of the patients in LVA group had intraoperative ischemic episodes and no patients required any blood transfusion during coronary grafting, it can be concluded that low volume autologous blood can be safely withdrawn in selected patient group posted for off pump coronary artery bypass graft surgery without posing additional risk to these vulnerable patients. (Table 2)

Interesting observation is that during first and fourth hour of recovery period, amount of blood drainage is significantly reduced in LVANH group but after twenty four hours amount of total blood darin is comparable. Possible explanation is this may be due to replacement of transfused pleatlets and coagulation factor with fresh autologous blood in LVANH group. (Table 3)

Total number of allogenic blood transfusion requirement was also not statistically different. Patients were extubated, shifted out of intensive care unit and discharged home with comparable time periods. (Table 3)

No statistical significant difference was observed in hematocrit, leucocyte count, platelets count, ACT values and serum creatinine values at all predefined point of times. (Table 4).

Authors acknowledge that autologous blood transfusion is not without adverse events. Acute hemolytic reactionshas been documented due to mistaken transfusion to a different patientin literature. Bacterial contamination of collected blood,hemodynamic instability and acute coronary events were other reported complication of autologous blood transfusions ${ }^{15}$. But no such complications were noted in the present study. This may be due to prudent technique and may also related to low volume of autologous blood withdrawn from the patients. Blood transfusion requirements post off pump coronary bypass surgery were comparable in both groups and amount of blood required not significantly different, this observation annul any conclusive advantage of low volume acute hemodilution transfusion in these cases after four hours of surgery.

No patient in any of the groups suffered major adverse cardiac event and all patients discharged home with satisfactory recovery within 10 day of surgery. (Table 5)

\section{Conclusion}

This study suggested that low volume autologous blood transfusion procedure is safe and can be done without any added risk to selected patients those are posted for off pump cardiac surgery. Actual benefit of this technique on reduction of blood loss is seen in first four hours of recovery 
but no added advantage is gained in post four hour period. Authors recommended large scale multicentre study with long follow up period for definitive conclusions.

\section{References}

1. Mangu HR, Samantaray A, Anakapalli M. Blood transfusion practices in cardiac anaesthesia. Indian J Anaesth 2014;58:61621

2. Barile L1, Fominskiy E, Di Tomasso N, Alpìzar Castro LE, Landoni G, De Luca M,: Acute Normovolemic Hemodilution Reduces Allogeneic Red Blood Cell Transfusion in Cardiac Surgery: A Systematic Review and Meta-analysis of Randomized Trials..Anesth Analg. 2017 Mar;124(3):743-752.

3. Matot I, Scheinin O, Jurim O, Eid A: Effectiveness of acute normovolemic hemodilution to minimize allogeneic blood transfusion in major liver resections. Anesthesiology. 2002 Oct;97(4):794-800.

4. Mohr R, Goor DA, Yellin A, Moshkovitz Y, Shinfeld A, Martinowitz U: Fresh blood units contain large potent platelets that improve hemostasis after open heart operations. Ann Thorac Surg 1992; 53:6504

5. Paul G., Loubser MB:Use of acute normovolemic hemodilution for blood conservation during off-pump coronary artery bypass surgery Canadian journal of anesthesia June 2003, Volume 50, Issue 6, pp 620-621|

6. Gross JB : Estimating allowable blood loss : corrected for dilution Anesthesiology; 1983, 58 (3); 277-80

7. Stover EP, Siegel LC, Parks R, Levin J, Body SC, Maddi R, et al. Variability in transfusion practice for coronary artery bypass surgery persists despite national consensus guidelines: a 24-institution study. Institutions of the Multicenter Study of Perioperative Ischemia Research Group. Anesthesiology 1998;88:327-33
8. Goodnough, L.T., Johnston, M.F., and Toy, P.T. The variability of transfusion practice in coronary artery bypass surgery. Transfusion Medicine Academic Award Group. JAMA. 1991; 265: 86-90

9. Herregods, L., Moerman, A., Foubert, L. et al. Limited intentional normovolemic hemodilution (ST-segment changes and use of homologous blood products in patients with left main coronary artery stenosis) . J Cardiothorac Vasc Anesth. 1997; 11: 18-23

10. Practice Guidelines for Perioperative Blood Management An Updated Report by the American Society of Anesthesiologists Task Force on Perioperative Blood Management* Anesthesiology 2015; 122:241-75

11. Ela, Y., Emmiler, M., Kocogullari, C., Terzi, Y., Sivaci, R., \& Cekirdekci, A. Advantages of Autologous Blood Transfusion in Off-Pump Coronary Artery Bypass. The Heart Surgery Forum, (2009). 12(5), E261-E265.

12. Bryson GL, Laupacis A, Wells GA. Does acute normovolemic hemodilution reduce perioperative allogeneic transfusion? A meta-analysis. The International Study of Perioperative Transfusion. Anesth Analg 1998;86:9-15.

13. Casati V, Speziali G, D'Alessandro C, Cianchi C, Antonietta Grasso M, Spagnolo $\mathrm{S}$, et al. Intraoperative low-volume acute normovolemic hemodilution in adult openheart surgery. Anesthesiology 2002;97: 36773.

14. Segal JB, Blasco-Colmenares E, Norris EJ, Guallar E. Preoperative acute normovolemic hemodilution: a meta-analysis. Transfusion 2004;44:632-44

15. R.E. Domen MD Adverse reactions associated with autologous blood transfusion: evaluation and incidence at a large academic hospital. The journal of AABB Trnasfusion March 1998, Volume38, Issue3 Pages 296-300. 